\title{
Methological Approaches of Seminal Importance for Synergetic Education and Social and Solidarity Economy in Promoting Creativity and Innovation
}

\author{
Panagiota Vathi, Dimitrios Kapogiannis, Vaggelis Politis-Stergiou \\ Technological Institution of Western Greece, Patras University, Greece
}

\begin{abstract}
This paper examines whether and in what ways the education system and the pedagogical culture particularly prevailing in Higher Education could be enriched with an alternative pedagogical model. A model that is differentiated from the prevalent pedagogical concepts is inspired by values and principles that form the core of a synergetic education and a social and solidarity economy. From an epistemological perspective, "associationnisme" that social and solidarity economy promotes is at stake and education must play an important role. The paper also examines the attitude of students towards such a perspective, mainly through exploring the current options as well as its potential expansion thereof in a way that promotes creativity and innovation. This study draws on previous research by P. Vathi (2014) on the topic of "A multidimensional-interdisciplinary approach and evaluation of University students' creativity, with emphasis on the utilization of statistical analyses" in order to assess the influence of education on students' creativity.
\end{abstract}

Keywords: synergetic education, social and solidarity economy, creativity, innovation

\section{Introduction}

Successive studies in the field of economic and social history and historical demography have shown that large population movements - due to environmental disasters, wars, border changes, and other extraordinary economic and social circumstances, as those experienced in recent years - created situations which have been effectively addressed by the contribution of a "bottom-up" economy, like Social and Solidarity Economy.

In our previous article (Kapogiannis \& Politis-Stergiou, 2011), we had an opportunity to point out the importance of recourse to the productive factor of "jobs" that were abundantly available in Social Economy institutions (the well-known attempt of farmer and middle class refugee recovery) in the period after the Balkan Wars and the Asia Minor Catastrophe for the subsequent course of Greek economy and society.

In our era, the economic, social, and value crisis and the way to address it have led to thousands of unemployed, semi-employed, and precariously employed, while they have also limited the potential for economic prosperity that had been artificially cultivated by a tenuous developmental model in the previous

Panagiota Vathi, lecturer, Ph.D. on Education, Primary Education, Patras University, Greece.

Dimitrios Kapogiannis, associated professor, Ph.D. on Social and Solidarity Economy, Technological Institution of Western Greece, Patras University, Greece.

Vaggelis Politis-Stergiou, emeritus professor, Ph.D. on Financial Anthropogeography, Business Administration, Technological Institution of Western Greece, Patras University, Greece. 
period. This model thrived and depended on the cultivation of individualistic behaviors, which were often embedded in and reproduced by the dominant pedagogical culture.

Therefore, a change of the developmental model cannot arise only from a new technocratic design, but from another model of social behaviour and pedagogical concept.

The search for viable, long-term solutions triggered again the need to explore-given the excessive availability of the productive factor of employment - alternative models of education, personal development, and social behaviour. After the onset of the crisis, alternative economy networks in various forms have been created in many regions of Europe. Today, there are thousands of unemployed young people who return to the countryside after finishing their studies and establish productive cooperatives, renewable energy cooperatives etc., while networks have also been established for the exchange of goods without using money as a medium of exchange. This is also the case in large cities, where pan-European centers of goods and services exchange, tenant cooperatives, housing cooperatives, etc., are spreading as they meet actual needs of society. Indeed, their action is supported by an ever-expanding social base, such as handicraft societies, craft and micro-industrial cooperatives, etc.

As important researchers in the field of Social Sciences emphasized, "hitherto unknown experience horizons and learning processes open up in these microeconomy communities. The discover new ways to organizing their lives, based on mutual assistance, social and economic equality and the strengthening of social solidarity relations".

The values of the co-operative movement cultivated through a synergetic education and the corresponding practices that undertake to implement institutional structures of Social and Solidarity Economy (formal and informal versions thereof) contribute, among other things, to a reorientation of education, society, and the economy. Besides, as already pointed out: "the co-operative movement is an economic movement that employs education...", it is argued (however) that it is "... also true that the co-operative movement is also an educational movement, a new culture that uses economic action".

This is true to the extent that there is an osmosis (Kapogiannis, 2011, pp. 72-73) of principles and values, such as solidarity, equality, responsibility (self-responsibility), self-help, democracy, self-motivation, self-education, self-expression, self-confidence, self-organization, and self-management, which are inherent to "genetic code" of Social/Solidarity Economy.

In particular, we can detect interrelations, mutual feedback and support, as well as factorial synergy, first among responsibility, self-commitment, self-organization, self-help and second among self-expression, creative initiative, and horizontal democratic organization, as well as among self-education and self-motivation on the one hand and strong self-confidence and self-management, on the other hand.

In other words, the practical application of most of these values and principles, even if not regarded as an end in itself, may be a derivative of synergetic action and can constitute a new "base" (or motivation) for their further spread.

This is true to the extent that some constitute basic human values, especially when they are also interwoven with cost-effective practices.

In particular, one of the hardest difficulties arising for the productive reconstruction that is much sought after in times of crisis, with proper use of the institutional system of Social and Solidarity Economy, is the lack of previous relevant experience. This is due, among other things, to the fact that the existing education system and the socialization system, in general, do not provide essential elements of learning as regards self-organization. 
This is why, according to Parnell (2000), a relevant preliminary training is required for existing and potential holders of executive positions in Social Economy institutions. As he pointed out: “...More often than not there is a lack of confidence in people who could contribute the most. Programmes should be designed to enhance people's self-confidence and to develop their skills so that they can express not only their own views, but also those of other members...." (pp. 110-111).

This is particularly true as, by developing the skills for self-organization, younger generations are now able to realize that they can, using their own means and methods and not as mere order executors who mechanically reproduce them but as conscious actors, do things that promote learning and their own life, namely, as Bourdet and Guillerm (1981) said, become "on their own creators of their own lives". Therefore, collective action in everyday life, action defined by young people themselves, will allow them to realize their power and defend their rights, thus building their self-confidence.

In this paper we therefore try to examine whether a synthetic result is achieved which is greater than the sum of the individual components, when there is synergy between institutions and actions inspired both by the values and principles of cooperative education and of Social and Solidarity Economy. The above position starts from (and includes) the admission that this synergy may contribute to the formation of a new developmental model, as its leads to the promotion of creativity and innovation, using a different path from that of individuality and mechanical reproduction of knowledge.

The paper contains two parts: the theoretical part, which presents the role of an alternative education, embedded in the prospect of an economy with relevant value content that promotes creativity and, consequently, innovation and the research part. This second part presents data and uses the conclusions of a research made at the University of Patras, which shows the level of cultivation of students' creativity during the teaching-learning-assessment process, while considering the demographic components of the subject under study (Vathi, 2014).

\section{Towards an Innovative Education, Inspired by Social and Solidarity Economy}

\section{The Need to Release the Creative Potential and the Horizon for Collective Orientation}

Unblocking and release of the creative potential. The usual criticism exercised on the existing education system is that it establishes procedures for transmitting knowledge, limited to its reproduction, without providing incentives for widening the horizons of the learners.

Many attribute this fact to the "exam-centered" (Aggelopoulos, 2007, pp. 61-67) nature of education, particularly to the "destructive link between education and university admissions" (Babiniotis, 2010). In fact, however, it seems that this is due to overall (structural) causes that discourage the creation and cultivation of a critical spirit. A reasonable explanation put forward by leading educator Paulo Freire, which was also adopted by Noam Chomsky among others, is that, as a rule, "official" Education systems are also oriented "... to maintaining existing social and economic structures, rather than changing them" (Chomsky, 2009, p. 34).

For example, the findings of important educators and social philosophers (such as Ferrer, Godwin, etc.) have now become widely accepted; according to these, the hierarchical structure of industrial society and certain types of personality traits that the "official" education system developed in the specific type of society were, as a rule, compatible (Joel Spring, 1987, pp. 22-24).

In connection with the above, it can be argued that, within the framework of Greek society, the "official" education system not only discourages critical and creative thinking (Aggelopoulos, 2000), but rather through 
the "sacred" examinations creates mechanisms that undermine the system of knowledge production.

We may rightly argue that in essence this usually works as a retention mechanism that prevents the release of the creative potential of young people, who seek in vain channels to use it. This is also evidenced by the enthusiasm displayed each time opportunities for creative self-expression arise, as also confirmed by the research findings listed below.

Therefore, the demand for the gradual transition from the existing education system to a different one, orientated towards new social and collective horizons, becomes increasingly urgent-especially under crisis conditions. The question, namely, is the transition from a system that supports and reproduces the same system of values to another education system; a system that is inspired by the values of solidarity and cooperative movement, a system instigating knowledge production processes on new terms; a system that will connect "indentifying and covering needs with the knowledge production processes", mainly through using the new options offered by “...the forms of peer to peer to peer production and solidarity economy" (Linardos-Rylmon, 2014) and which will provide leverage to innovation and creativity.

The social experiments that currently, through cracks in existing institutions, take place and are linked to a social and solidarity economy, are a preliminary training for autonomy (see below) and creativity education.

It is clear that, under the conditions of an "emergency" economy triggered by the crisis, the "melting" (according to Sartre's wording ${ }^{1}$ ) of existing hetero-management or heteronomy institutions is accelerated, which raises the need to use the self-governing institutions of Social and Solidarity Economy. Through institutional pluralism and the social experimentation that it stimulates, the appropriate institutions will emerge each time to release the creative potential encompassed by the new, and currently trapped, productive forces. This insofar as self-management sets, as shown in recent studies (Nikolopoulos, 2013, p. 69) appropriate conditions for the release of vast creative forces that remained inactive, mainly due to the authoritarian educational model and the hierarchical model of economy and society organization.

At this point, it should be noted that for years, in various countries (including Greece ${ }^{2}$ ), important initiatives have been taken and there have been proposals for the use of institutions, such as cooperative schools $^{3}$ moving towards that direction (Baudrit, 2007, p. 20). With similar collective orientations, other collective activity forms were also proposed in the 20th century, such as school communities and student collectives (Baudrit, 2007, pp. 19-20), as well as other included in a self-management perspective, as they are deemed compatible with synergetic pedagogical concepts that emphasize on the promotion of creativity.

\section{Positive Sociotropism: A New Horizon for Collective Orientations}

In order to study the decryption of internal mechanisms that create osmosis among society, economy, education, creativity, and innovation, it is useful to enrich our conceptual vocabulary.

This attempt is aided by the introduction of a new term in the scientific dialogue, which, under new circumstances, is now being carried out in relation to the above cohesions. It is not a "neologism", but a term that provides a positive approach to the development and orientation of the entire venture. Positive

\footnotetext{
1 Y. Bourdet and A. Guillerm (1981), p. 275.

2 Klimis (1993).

3 The central idea of cooperatives: "everyone contributes to the development of the social structure, everyone gets what they need" could be also transferred to school. Based on this principle, children could develop their personalities within a rational community which they serve and which serves them (Freinet, 1977, p. 18). Therefore, cooperative schools operate as cohabitation communities where pupils live together, work together, learn together, determining on their own the operating rules (Baudrit, 2007, p. 20).
} 
sociotropism means the special case of tropism ${ }^{4}$ in which individual or collective actors are oriented to meeting the needs of society and the production of the social fabric, at priority (De Angelis, 2013, pp. 138-139) and are inspired by common pedagogical principles and values.

Before specifying the cohesions, as far as education is concerned, it is useful to note the important distinction between instrumental learning and education of the autonomy. The element that differentiates one from the other is that the latter starts with the fundamental assumption that the autonomous ${ }^{5}$ society consists of autonomous individuals and, conversely, that truly autonomous individuals "... can only exist in an autonomous society and through an autonomous society" (Kastoriadis \& Cohn-Bendit, 1981, p. 88). For Kastoriadis, who often revisited this matter (Latouche, 2014, p. 28), this type of education “... for and towards autonomy, a education that makes everyone who had it - and not only the pupils - constantly doubt themselves to learn to act with conscience of their actions ..." is de facto "... a matter that begins with the birth [of the individual] and ends only with its death (Latouche, 2014, p. 66).

At this point, it is important to also note the significance of self-education, in this respect. Self-education is defined, mainly, as:

A life-long attitude, an attitude towards education, oriented towards the elimination of sovereign and conventional culture, the cultivation of the intention to research, critical thinking and creative expression, the self-determination of personal and public life, contributing to social development and the emancipation of man. (Vergidis in Vergidis et al., 2011, pp. 104-129)

"Self-education pedagogy refers to education as an overall social phenomenon, namely in all processes that "educate" (form) people and not just those that are restricted by educational institutions" (Livieratos, 1983).

It is therefore clear that there is a common ground, where cooperative education-as an essential education of autonomy - life-long learning, self-education, Social Economy and social capital meet.

Going back to the matter that is the quintessence of the Social and Solidarity Economy institutions, as summarized in the well-known position of Rob. Owen (one of the founders of the Cooperative movement), an alternative social organization needs to be such as to "... harmonies the personal interests with the interests of society" (as cited in Kapogiannis, 1990, p. 26).

Nowadays, this debate on the institutional and conceptual equipment of Social and Solidarity Economy increasingly takes on additional dimensions. This is true in so far as, as mentioned above, that it is enriched and fertilized by more specific, similar ideological and scientific processes which, from different starting points, tend to theoretically link "social capital" and "cooperative creativity" to the wider field of Social Economy (of solidarity or of the market $)^{6}$ as some consider them as correlating with the variety of fertile social and/or institutional experiments (Varcarolis, 2012; Potamianos, 2013, pp. 71-72; pp. 189-193) and others view them as correlating the promotion of innovation (European Commission, Nasioulas, 2013, pp. 63-65).

It is not, perhaps, a mere coincidence that in recent years social entrepreneurship is at the focus of the European Commission, as an alternative form of entrepreneurship. It is, indeed, proposed as the form that is

\footnotetext{
4 Tropism is defined as "an orientation reaction towards (positive tropism) or away from (negative tropism) a stimuli" (Papyrus Larousse Britannica, 1996).

5 The concept of autonomy is used here as opposed to the concept of heteronomy which is its opposite aspect and which (autonomy) must not be restricted (as per the liberal tradition) simply to the emancipation of the individual from traditions (Latouche, 2014, p. 21).

${ }^{6}$ As to this distinction, see Nikolopoulos \& Kapogiannis, 2011, p. 23.
} 
more compatible with the promotion of innovation, compared to other alternative forms of entrepreneurial activity. This is also apparent from the fact that since October 2011, an initiative of the European Commission has been launched under the title: "Social business initiative - Creating a favorable climate for social enterprises, key stakeholders in the social economy and innovation" (Nasioulas, 2013, p. 14).

However, what are the specific correlations that bring Social Capital ${ }^{7}$ and Social Economy together? Reciprocity and trust are the elements that create close links between Social and, in particular, Solidarity Economy and Social Capital (Bevort \& Bucolo, 2006; 2008, p. 93). The rules of reciprocity generate trust among individuals as well as the solidarity principles within and beyond solidarity structures (Bevort \& Bucolo, 2006; 2008, p. 93). Therefore, a member of a solidarity structure creates Social Capital, using and adding value to the social bond, through reciprocity. Each member of a group benefits from the different experiences of others and all members together make them available to a wider, local "public" ("market"), in an autonomous public-common area (Bevort \& Bucolo, 2006; 2008, p. 92). The non-hierarchical-equal and consultative association of individuals creates activities for a group of beneficiaries or, through self-organization, collectively addresses a need, which the individual-members want to satisfy, too (Bevort \& Bucolo, 2006; 2008, p. 92).

The socio-political priority of Social and Solidarity Economy is rooted in the Social Capital (Papadopoulos, 2005, pp. 204-205), in the sense that its existence requires the activation/use of Social Capital, which creates institutions and associations of the tertiary sector. At the same time, institutions and associations/enterprises enhance the Social Capital in a local economy and society (Papadopoulos, 2005, p. 205). As already pointed out, the proximity services of Solidarity Economy are based on day-to-day practices of local populations, the relationships and symbolic exchanges, values, expectations, and desires of users. Through this public or common micro-space of proximity, services supply and demand are created - through reciprocity and trust—by the interaction of the individuals and/or entities involved (Laville, 1994, pp. 82-83; p. 85).

Among these, the institutions of Social and Solidarity Economy appear to hold a special place in that, as mentioned above, they are considered appropriate for contributing to the promotion of innovation and creativity, while in the context of "cooperative creativity", they are products of fertile and creative social experiments, constituting at the same time significant institutional innovations. ${ }^{8}$

Cooperative education, on the other hand, is distinguished by feature-values that promote creativity as a value that is sought after over time ${ }^{9}$ (horizontal organization of employment relationships, rotation, self-management), which differentiates it from the traditional and established model of education, which places much emphasis on competition and individuality. Therefore, self-management in the context of education

\footnotetext{
7 "Social Capital", as per P. Bourdieu, J. Coleman, and R. Putnam, "is the total of non-financial resources, real or imaginary, attributable to individuals, a group or a network of social relations and characterized by trust, reciprocity and mutually accepted behavioral rules, which facilitate the cooperation and collective action of the people, in the general interest. Therefore, social capital can be understood as a resource that stems from collective action and can have results at a very wide economic and social scale" (Karamanou, 2003, p. 3). Social Capital accumulation is achieved by: voluntary participation in networks, reciprocity, trust, rules (norms), community (Karamanou, 2006, pp. 6-7).

8 These institutions and institutions inspired by the cooperative movement in general are considered to encompass a dynamic proponent of creativity, especially in so far as "cooperativity" tends to be not only a production relationship but also a productive force (Dietrich, 1983, p. 75; Lefebvre, 2004, pp. 40-44; Baudrit, 2007, p. 20; p. 23; Kapogiannis, 2010, pp. 72-73; De Angelis, 2013, pp. 33-35; p. 138).

${ }_{9}$ See the evaluation of the experience of the University of Paris 8, by Vincennes. Guy Berger, Maurice Courtois, Colette Perrigault, Folies et raisons d'une Universite: Editions Petra, Paris 2015, б.215.
} 
should return ${ }^{10}$, as in the modern, complex working and social environment, the skills required by citizens and workers are differentiated, a fact that is reflected in the pursuit of training for European and international players, where creativity emerges as a basic skill for integration in the labor market (Vergidis, 2000; Karatzia-Stavlioti, 2005; McKinsey Study, 2013; Creative Europe Programme, 2014).

\section{The Favorable Environment for Creativity and Innovation}

Learning and creativity involve fundamental processes of cognitive change and, under normal circumstances, are interrelated (e.g., Candy \& Edmonds, 1999).

Numerous and different definitions have been given for creativity, among which the following is deemed as the most general and comprehensive:

Creativity is defined as the ability/skill of the individual to produce new or original ideas, to have insights, to transform and discover, to manufacture objects which are recognized by the experts as having a distinct scientific, aesthetic, social or technological value. The basic criterion for the assessment of Endeavour as "creative" is innovation, but it is also required to be useful and acceptable, even if its value changes over time. (Vernon, 1989)

Moreover, creativity is defined as the ability to change the mental context and to find an alternative solution to view and address the problem from a new perspective. It is connected with mental functions and with emotions (Trilianos, 1997).

It is argued (Kampylis, 2010, p. 39) that in order to approach these components, it is necessary to thoroughly investigate the relationships between personal, cognitive, social, cultural, and environmental factors that potentially affect the creative potential of the individual.

Researchers from various scientific fields and with different theoretical backgrounds approach the above figure in different ways. It seems that this figure is a satisfactory approach to the interpretation of creativity, as it incorporates important elements of the personality, cognitive and developmental psychology and sociology. It schematically represents the common view of researchers (Magyari-Beck, 1999) that creativity is a complex interactive relationship between individual and situations, which is affected by the experiences of the past as well as by the relevant context. This schematic representation of the factors interacting in the manifestations of creativity is useful for any relevant research design.

The cognitive approach to creativity alone cannot interpret it, but it still is an important stage of investigation since, in this light, creativity is thought to arise from the usual cognitive processes, to be part of the cognitive skills of every human being, and it can therefore be facilitated and enhanced through an appropriate educational process (Finke, Ward, \& Smith, 1992). In particular, it is argued that "the understanding of creativity will not be complete without the detailed and rigorous exploration of the cognitive processes from which original ideas emerge and through which the creative perspective of these ideas is recognized" (Ward, 2001). It is, therefore, clear how important it is to focus on the cognitive processes that lead to creativity, as the better their understanding is, the more they can be improved through education and training. ${ }^{11}$

As shown by the study of the answers given for this research, students believe that their creativity is

\footnotetext{
${ }^{10}$ It is well known that in the past (before the 1960s), those involved in educational policy design had already developed a perception towards that direction (e.g. cooperative schools).

${ }_{11}$ Researchers (e.g., Goldstein \& Gessner, 1988) are of the opinion that, since training is now aimed at systematic learning not only of skills, rules and concepts, but also of attitudes and behaviors, it cannot but at least involve a deeper understanding of the issues (Kokkos, 2007).
} 
cultivated through their active participation in the teaching/learning process (essays, workshops, projects, clinics, participation in seminars/conferences, etc.), but also through linking Curricula to their potential future professional field and the job market. This concern refers to all levels of education, as a different teaching process may inspire learners with the interest to explore, question, and acquire further knowledge that will lead to a different way of thinking and perception, ultimately enhancing their creativity.

As early as 1980, I. Solomon, responding to international trends, presented in his work the self-education model, with the following key words: apprenticeship, willingness, use of knowledge through collaborative processes, connection of knowledge, school, and society (concepts related to the factors, which, according to the research findings, contribute to the promotion of creativity) recurring in his work (Asimaki, Kamarios, \& Kousoutrakis, 2011, p. 21 et seq.). A typical quote is:

The first general problem, both philosophical and practical, is the relationship between freedom and learning. Freedom in learning requires awareness and personal responsibility, solidarity and mutual respect, qualities that the lack of freedom and the disciplinarity of our learning experiences so far, as well as the overall predominant life, have not cultivated. (Solomon, 1991)

\section{Demographic Components and Findings of a Research on the Cultivation of Creativity in Higher Education, in the Light of an Alternative Approach to Education}

\section{Demographic/Personal Characteristics of Research Subjects ${ }^{12}$}

The tables below (see Tables 1-11) summarized the demographic/personal characteristics of the students of the University of Patras who participated in the research.

Table 1

Distribution of Research Participants by Gender

\begin{tabular}{ll}
\hline Sex & Rate (\%) \\
\hline Men & 40.6 \\
Women & 59.4 \\
\hline
\end{tabular}

12 The empirical research was carried out on students of the second and fourth year of studies of the Departments of Biology, Electrical and Computer Engineering, Medicine, Primary School Education (as representative of the schools of Natural Sciences, Engineering, Health Sciences, Humanities and Social Sciences of the University of Patras) as well as of the independent-at the time of the research-Departments of Economic Sciences and Business Administration and is a kind of case study of the University of Patras.

For the collection of data a specially designed questionnaire of 63 questions was used, which, based on the bibliographic review that preceded it, contained questions about the demographic and personal characteristics of the respondents and Likert type questions concerning a person's assessment of the probability and the level of truth of a proposal (Oppenheim, 2005). Questions of this type that were included in the questionnaire seek out student assessments for activities they participate in and the contribution of their studies in this direction. Questions on the creative activities that the respondents have participated in their lives, before and during their studies, cover, according to the literature (e.g., Hocevar, 1979; DeHaan, 2009) mainly in the following areas: arts/crafts, theatre/music/performances, mathematics and natural sciences, speech expression/manipulation, mixed creative activities. Moreover, open-ended questions are provided in order to collect further information about their views on the role of their studies in developing their creativity.

During the spring semester 2011-2012, the questionnaire was given to a total of 434 students of the selected Departments. The questionnaires were distributed, in consultation with the teachers, during the compulsory courses of the Departments, thus ensuring participation of active students of the University in the research. During the main phase of the research, the researcher distributed and directly collected the questionnaire to the students-subjects of the research. The questions were then encoded, depending on their type and the dominant research practice. Subsequently, the data was entered into the statistical package SPSS v.17.0 and analyzed, using descriptive statistics techniques and then applying inferential statistics techniques on the dependent variable "level of creativity cultivation", in order to investigate and highlight possible parameters that are related to the development of creativity. Finally, we made a synthetic-comparative assessment of the different analyses findings, to allow for a multifaceted approach on the matter. 
Table 2

Distribution of Research Participants by the Population of Their Place of Origin

\begin{tabular}{ll}
\hline Population of place of origin & Rate $(\%)$ \\
\hline Less than or equal to 9,999 inhabitants & 22.5 \\
$10,000-9,9999$ inhabitants & 54.29 \\
More than 10,0000 inhabitants & 23.21 \\
\hline
\end{tabular}

Table 3

Distribution of Research Participants by Type of Graduation Senior High School

\begin{tabular}{ll}
\hline Type of graduation senior high school & Rate (\%) \\
\hline Public & 87.1 \\
Private & 8.3 \\
Experimental & 4.2 \\
Music & 0.2 \\
Night & 0.2 \\
\hline
\end{tabular}

Table 4

Distribution of Research Participants by Profession of Parents

\begin{tabular}{llll}
\hline Profession of father & Rate (\%) & Profession of mother & Rate (\%) \\
\hline Agriculture-fishing-livestock farming & 9.2 & Agriculture-fishing-livestock farming & 2.4 \\
Construction & 11.8 & Trade & 4.9 \\
Trade & 5.9 & Accommodation-catering & 2.8 \\
Accommodation-catering & 4.7 & Professional-scientific-technical activity & 6.3 \\
Professional-scientific-technical activity & 9.7 & Administrative activity/public administration/defense & 23.3 \\
Administrative activity/public administration/defense & 32.2 & Education & 16.1 \\
Education & 9.5 & Human health-social care & 8 \\
Human health-social care & 5.5 & Other professional activities & 7.3 \\
Other professional activities & 11 & Housewife & 26.8 \\
Unemployed & 0.2 & Unemployed & 2.1 \\
\hline
\end{tabular}

Note. Source: The categorization of the professions was based on the National Classification of Economic Activities, 2008 Economic Activity Codes, issued in accordance with Regulation (EC) 1893/20-12-2006.

\section{Table 5}

Distribution of Research Participants by Educational Level of Father

\begin{tabular}{ll}
\hline Father's education level & Rate $(\%)$ \\
\hline Higher education degree & 13.7 \\
Senior high-school leaving certificate & 13 \\
High-school leaving certificate & 28.5 \\
Primary school leaving certificate & 44.8 \\
\hline
\end{tabular}

Table 6

Distribution of Research Participants by Educational Level of Mother

\begin{tabular}{ll}
\hline Mother's education level & Rate $(\%)$ \\
\hline Higher education degree & 8.1 \\
Senior high-school leaving certificate & 7.3 \\
High-school leaving certificate & 37.8 \\
Primary school leaving certificate & 46.8 \\
\hline
\end{tabular}


Table 7

Distribution of Research Participants by Number of Their Siblings

\begin{tabular}{ll}
\hline Number of siblings & Rate $(\%)$ \\
\hline 0 & 2.9 \\
1 & 69.3 \\
2 & 16.2 \\
More than 3 & 11.6 \\
\hline
\end{tabular}

Table 8

Distribution of Research Participants by Number of Their Friends

\begin{tabular}{ll}
\hline Number of friends & Rate (\%) \\
\hline Number of childhood friends: no more than 5 & 60.17 \\
Number of childhood friends: more than 5 & 39.83 \\
Number of friends from adulthood: no more than 5 & 19.65 \\
Number of friends from adulthood: more than 5 & 80.35 \\
Number of Facebook friends: 0 & 4.8 \\
Number of Facebook friends: no more than 100 & 14.78 \\
Number of Facebook friends: more than 100 & 80.42 \\
\hline
\end{tabular}

Table 9

Distribution of Research Participants by Grade of Admission to University

\begin{tabular}{ll}
\hline Grade of university admission & Rate (\%) \\
\hline Under 15 & 0.2 \\
$15-18$ & 34.58 \\
Over 18 & 65.22 \\
\hline
\end{tabular}

Table 10

Distribution of Research Participants by Participation in School Programmes

\begin{tabular}{ll}
\hline Program & Rate $(\%)$ \\
\hline Flexible zone & 19.2 \\
Health education & 25.5 \\
Environmental programme & 47.9 \\
Comenius programme & 6.2 \\
\hline
\end{tabular}

Table 11

Distribution of Research Participants by Average Grade at University So Far

\begin{tabular}{ll}
\hline Average grade at university & Rate $(\%)$ \\
\hline Under 6.5 & 38.87 \\
$6.5-8$ & 49.87 \\
Over 8 & 11.26 \\
\hline
\end{tabular}

It is worth mentioning that $9.9 \%$ of the students participating in the research also worked at the time of their studies.

\section{Some Useful Research Findings, in the Light of an Alternative Approach to Education}

The following Table 12 shows the correlations between the demographic/personal characteristics of the students who participated in the research by their participation in creative activities, their views on the cultivation of creativity within the department they are studying, and the degree of their participation in activities of the University and of their city of study. 
Table 12

Correlations of Demographic/Personal Characteristics With the Averages Mean1, Mean 2, Mean 3

\begin{tabular}{llll}
\hline & $\begin{array}{l}\text { Participation of students } \\
\text { in creative activities } \\
\text { (mean 1) }\end{array}$ & $\begin{array}{l}\text { Students' views on the cultivation } \\
\text { of creativity within their } \\
\text { department of study (mean 2) }\end{array}$ & $\begin{array}{l}\text { Participation of students in } \\
\text { university and city activities } \\
\text { (mean 3) }\end{array}$ \\
\hline Number of siblings & 0.47 & 0.41 & 0.47 \\
Number of childhood friends & $0.61^{* *}$ & 0.52 & $0.57^{*}$ \\
Number of friends from adulthood & $0.53^{*}$ & $0.53^{*}$ & $0.56^{* *}$ \\
Number of Facebook friends & 0.44 & 0.46 & 0.46 \\
Leaving certificate grade & 0.44 & 0.42 & 0.4 \\
University grade & 0.42 & 0.46 & 0.44 \\
\hline
\end{tabular}

The overview of the findings shows a moderate correlation (0.61) between the number of childhood friends and student participation in creative activities, with students with a higher number of childhood friends showing a higher degree of participation in creative activities. This correlation is statistically significant at a $1 \%$ significance level. Moreover, moderate correlation (0.57) is found between the number of childhood friends and student participation in University and city activities, with students with a higher number of childhood friends showing a higher degree of participation. This correlation is statistically significant at a $5 \%$ significance level. This finding is interesting, in terms of the link between the sociability and the creativity of students.

There is also a moderate correlation between the number of friends from adulthood and the participation of students in creative activities (0.53), their views on the cultivation of creativity in their department of study (0.53) and their participation in university and city activities (0.56), with students with a higher number of friends from adulthood showing a greater degree of participation in creative activities, a less favorable view on the cultivation of creativity in their Department and a greater degree of participation in activities of the university and the city. These correlations are statistically significant at a 5\%,5\%, and $1 \%$ significance level, respectively.

More generally, research data suggest that students understand the great importance of investing in a type of education that is directly linked to creativity and the promotion of science and the arts, which will lead to innovation, in a society that is coherent and accepts diversity. However, according to the opinions of the students interviewed, their Departments of study do not meet these requirements.

It should be noted that any attempt to assess creativity could be compared to the respective attempts to quantify other qualitative characteristics of the individual, such as the culture of communication or political consciousness. In cases where the teacher asks not only a correct answer but a logical, critical approach, then the learner's thinking process is more important than the result of the task per se, namely, it is not enough to only assess the outcome achieved, but also the way the learner thinks, analyses, assesses, and interprets. The research highlighted the importance of using alternative teaching and assessment methods in this direction.

The teacher, depending on the type and level of education, can also contribute to the development of each learner's responsibility for their own learning. According to European Union directives, the teacher must also aim, in addition to cultivating responsibility, at promoting critical thinking and encouraging creativity and innovation (Mardas, 2001, p. 60).

This is possible if, for example, the teacher encourages learners to actively participate in the assessment process to form a clear view of their achievements and to feel the need for an on-going and stable attempt for self-improvement, which is a prerequisite for creativity development (Sawyer, 2006). 
The above findings are interesting as they are consistent with the view that collectivity, as expressed through the friendly relationships and the characteristics they cultivate in the personality of the individual, is associated with creativity and active participation in the community. The above conclusion, combined with the students' view, as evidenced by their answers to a relevant open-ended question: In what ways do you think that the Department of your studies and the University in general cultivates the creativity of students?, which described how their creativity is promoted through teamwork, through the exchange of views with their fellow students (Vathi, 2011. pp. 156-158), sets the tone of the education we need, as it meets the needs of our time. Even beyond the field of higher education, the influence of groups in the development of specific characteristics of young people identity is also highlighted by relevant researches, which focus on adolescence and the relationships developed at school (Christodoulou, 2014, p. 58).

\section{Conclusion}

Creativity is a predominantly human characteristic, but in modern times, as social parameters change rapidly, it has become of particular importance.

It has been shown that the promotion of creativity, which was a fundamental part of the preceding analysis, should not be limited in the framework of formal education of all levels, nor can it be exhausted as to how it can be cultivated. Considering that an important role in shaping the social self (Christodoulou, 2014, p. 78 et seq.) is played not only by formal education but also the education obtained through participation in social structures and structures of civil society, it is understood that participation in a cooperative education but also in structures of Social and Solidarity Economy contributes in shaping the social self in it, namely, in the discourse between "I" and "Me", where "me" in a way means the moral standards of the community (Christodoulou, 2014, pp. 78-79).

The arising discourse concerns mainly the reasons why creativity connects individuals to the society where they live and act and operates as a vehicle leading to the formation of a culture of sustainability, in the Social Capital. In this way, a proposal for education is formed, with the vision of acquiring Social Capital, as the spirit, the objectives and goals of Social and Solidarity Economy go beyond the coverage of emergency needs and permeate for life the society and the individuals that comprise it.

In this regard, it was important to highlight the importance of the synergy of an education inspired by the values of solidarity and co-operation and an economy like the social and solidarity economy, oriented towards shaping a new model of development, as it aims at promoting creativity and innovation, as shown above.

In a more tangible field, the processing of the research carried out at the University of Patras showed that although students consider it important to cultivate creativity in their studies, in their view, this is not a priority of their teachers. It is clear that many steps need be made towards an education that focuses on the cultivation of learners' creativity.

This concern refers to all levels of education (it also expands beyond the formal education system), as a different teaching process may inspire learners with the interest to explore, question, and acquire further knowledge that will lead to a different way of thinking and perception, ultimately enhancing their creativity.

Therefore, a new way of teaching-assessment is required, which will help students-future citizen to get the information, to process it on their own, judge it, compile it, present it, accept criticism on it and allow them, through creative collaborations and participation in groups, to perceive the world in a new way and with a healthy feeling; namely allow them to conquer important knowledge. Operation within groups is a form of user 
experience requiring active participation and is therefore valuable in the learning process and the learning process and educational experience.

Therefore, educationally appropriate forms and techniques of teaching and assessment are those that contribute to the achievement of a greater number of the desired individual and social goals of education, such as the cultivation of critical-creative thinking, the development of communication and collaboration skills, the formation of the social self $\mathrm{f}^{13}$ of young people based on these characteristics.

It is therefore clear that it is essential to develop an education, allowing learners to actively participate in the development of programmes that need their needs at institutional level, too. An example of a pedagogical unit with these characteristics, apart from cooperative schools which have historically been (M.D.Ф3/1085/Г1/1456/1-12-97) and still are a preliminary training for familiarization and addiction in the "culture of self-management" (ibid., Article 1, Paragraph 2), is "education camp" (Mendel \& Vogt, pp. 343-344) where participants are initiated in communal life, which is linked to the exercise of collective power and to the self-management and self-organization of the social, educational, and professional lives of the participants. Unfortunately, in Greek reality, the camp institution ends up reproducing the hierarchical structures of the system and is nothing but yet another tool for secondary socialization that is complimentary to the system and is simply limited to the dissemination of skills and behaviors.

It would therefore be important, if at least new curricula at Higher Education Institutions were aligned with the needs of the times and the relevant demands of students, emphasizing not only on the cognitive objects but also on their role in developing skilled, thoughtful, creative, and active citizens. Much more so, globalization has caused radical changes in almost all areas of human activity, including education (e.g., Hartley, 2003). Therefore, societies, such as the Greek, which used to be characterized by homogeneity, have now become multicultural, which requires appropriately trained citizens. Consequently, contemporary education is required to cultivate creativity, taking into account not only individual differences but also socio-cultural particularities, since, according to Burnard (2006): “... recognizing and understanding the socio-cultural dimensions of creativity enhances its position and cultivation within education" (Kampylis, 2010, p. 99). Besides, education is politics, in the sense that it is applied in a specific socio-cultural and economic context, reflecting the relevant political needs and intentions (McLaren, 2002; Kampylis, 2010, p. 99).

\section{References}

\section{Greek}

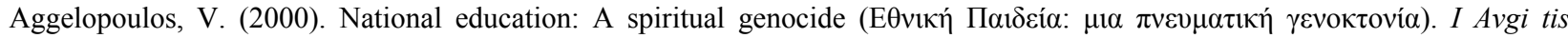
Kyriakis, 22-10-2000.

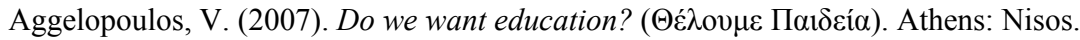

Asimaki, A., Kamarios, G., \& Kousoutrakis, G. (2011). For a poetic of educational landscape. Ten years after... to Iosif Solomon

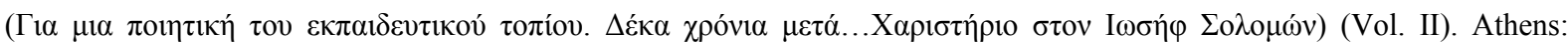
Alexandreia.

Babiniotis , G. (2010). Not a word for culture. To Vima, 13 June, 2010.

Christodoulou, M. (2014). Education and adolescence: A comparative study of the formation of social self in the life stories of secondary education pupils (Unpublished Ph.D. dissertation, Patras).

GG 1107/15-12-97, issue B

\footnotetext{
13 The social self develops as a result of a discourse between the "I" and the "Me", through which the individual takes decisions taking into account the "others", to the extent that the "Me" in a way means the moral standards of the community (Christodoulou, 2014, pp. 78-79) to which the individual participates.
} 
Hatzatoglou, G., \& Koulogliotis, N. (1979). Special teaching of specialty courses (for graduates of Economics, Law, AUEB, Piraeus University of Economics, Panteion University). Athens: SELETE.

Kapogiannis, D. (1990). Qualified executives-successful cooperatives of small and medium-sized enterprises. Nea epaggelmation viotechnon-emporon, 25(128), 26-27.

Kapogiannis, D. (2010). Organizations of professional and economic cooperation and vocational education and training: Aspects

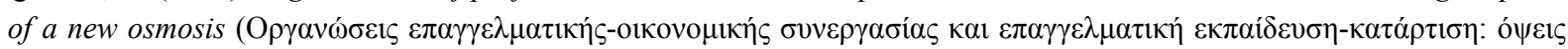

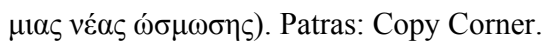

Kapogiannis, D., \& Politis-Stergiou, E. (2011). Effects of excessive population movements on land ownership and social economy. Tetradia Istorikis Dimografias (1st ed., Athanassopoulou), 6.

Karamanou, A. (2006). Social capital and migration, dissertation. Retrieved from www.karamanou.gr/gr/uploads/Documents

Karatzia-Stavlioti, E. (2005). The challenge of interdisciplinarity and the effectiveness of school in Greece and Europe. Sigritiki kai Diethnis Ekpaideftiki Epitheorisi, 5, 91-115.

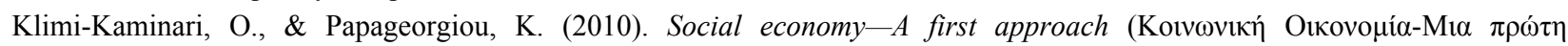
$\pi \rho \circ \sigma \varepsilon ́ \gamma \gamma ı \sigma \eta)$. Athens: Ellinoekdotiki Editions.

Klimis, A. (1999). Cooperatives in Greece. (Vol. 5). Athens: SEKAP.

Kokkos, A. (2007). Adult education as a distinct institutional and scientific field. Journal Dia Viou/Scientific Review for Lifelong Learning, 1, 45-48.

Kostas, A. (2013). Organizations and social enterprises in Greece. In K. Geormas (Ed.), Social economy-theory, experience and

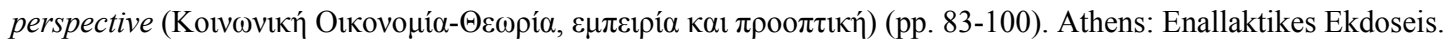

Law 4019/11 (GG 216 A/30.-9-2011): Social Economy and Social Entrepreneurship and other provisions.

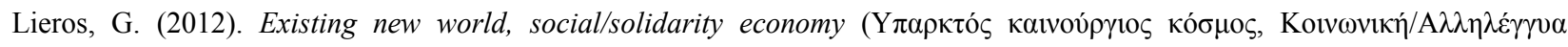
оъкоvонía). Athens: Oi Ekdoseis ton Synadelfon.

Lieros, G. (2013). Charity and solidarity. Drasi, 2-1-2013.

Linardos-Rylmon, P. (2014). Class consciousness or mass intelligence? I Epochi, 23-11-2014.

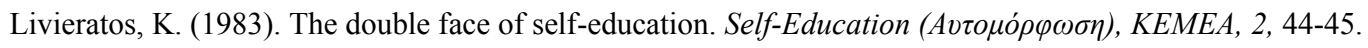

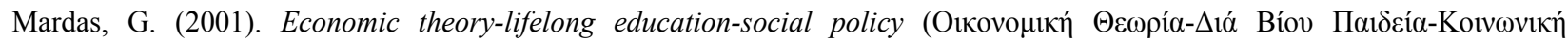
Подıєєиं). Athens: Papazisis.

Ministerial Decision $\Phi 3 / 1085 / \Gamma 1 / 1456 / 1-12-97$

Ministry of Education and Religious Affairs, General Secretariat for Adult Education, Institute for Continuing Adult Education.

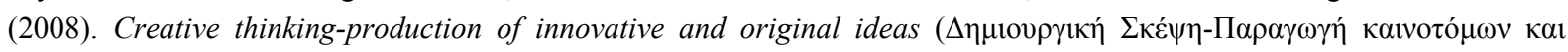

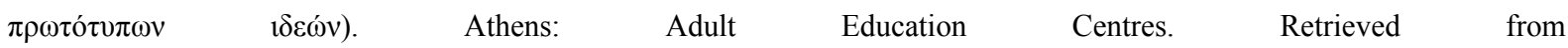
http://repository.edulll.gr/edull1/retrieve/3352/1008.pdf

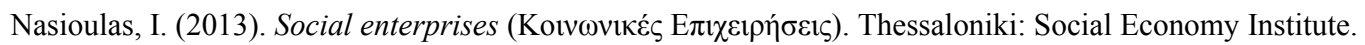

Nikolopoulos, I. (2013). Crisis, solidarity economy and social emancipation. Theseis, 123, 57-71.

Nikolopoulos, T., \& Kapogiannis, D. (2011). Social Economy of solidarity or of the market? I Avgi tis Kyriaki-Enthemata, 3-4-2011, p. 23.

Nikolopoulos, T., \& Kapogiannis, D. (2012). Alternative forms of economic networking-inter-cooperative collaboration between producers and consumers (pp. 345-355). N. Mpeopoulos and A. Koutsouris (Eds.). Paper presented at The 11th Conference of ETAGRO (Agricultural Economy Society), Agricultural University of Athens, 26-27 November 2010.

Nikolopoulos, T., \& Kapogiannis, D. (2013). Introduction to social and solidarity economy: The uncertain step of a potential (2nd

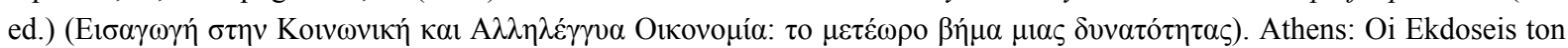
Synadelfon.

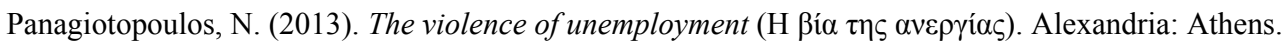

Papadopoulos, A. (2005). The importance of social capital for social economy (pp. 202-226). The social economy between the local and the global. Minutes of The 4th Scientific Conference of the Department of Cooperative Organisations and Operations (SSOE). Athens: Papazisi.

Papyrus Larousse Britannica. Athens: Papyrus, 58, 124-125.

Paraskevopoulos, G. (1993). The creative demolition of development (pp. 56-60). Nea Oikologia, November 1993.

Paraskevopoulos, G. (2001). Social capital, civil society and public policy. Epitheorisi Koinonikon Erevnon, 106, 43-46.

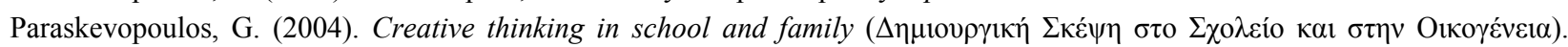
Athens: Ellinika Grammata. 


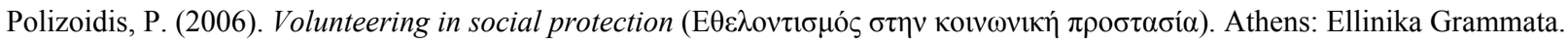
Potamianos, D. (2013). Solidarity days (A $\lambda \lambda \eta \lambda \varepsilon \dot{\gamma} \gamma v \varepsilon \varsigma \mu \varepsilon \dot{\varepsilon} \rho \varepsilon \varsigma)$. Athens: Potamos.

Solomon, I. (1991). Introduction to the issue of Basil Bernstein's cultural reproduction (pp. 15-39). In B. Bernstein (Ed.), Pedagogical codes and social control (I. Solomon, Trans.). Athens: Alexandria.

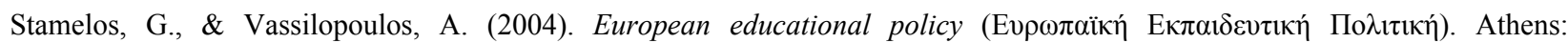
Metaichmio.

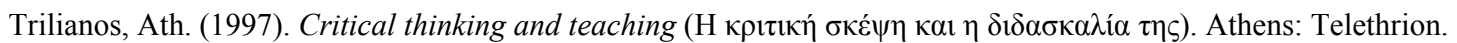

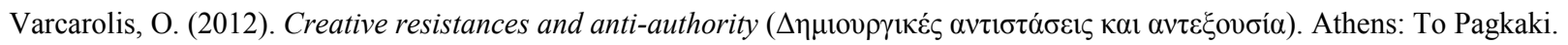

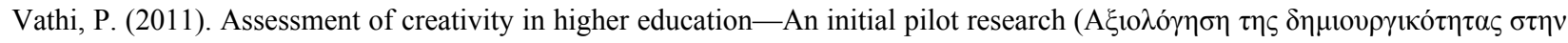

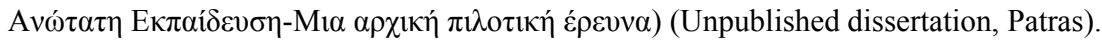

Vathi, P. (2014). Multidisciplinary-interdisciplinary approach and assessment of student creativity with emphasis on the

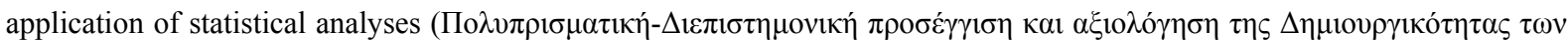

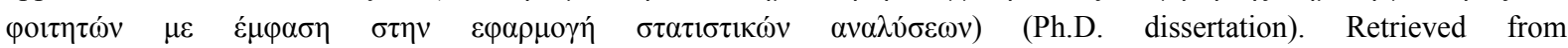
http://hdl.handle.net/10889/8013

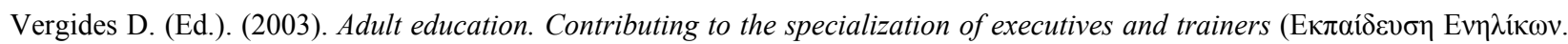
$\Sigma v \mu \beta 0 \lambda \eta ́ ~ \sigma \tau \eta v ~ \varepsilon \xi \varepsilon ı \delta ́ \kappa \varepsilon v \sigma \eta ~ \sigma \tau \varepsilon \lambda \varepsilon \chi \omega ́ v ~ \kappa \alpha \iota ~ \varepsilon \kappa \pi \alpha 1 \delta \varepsilon v \tau \omega ́ v)$. Athens: Ellinika Grammata.

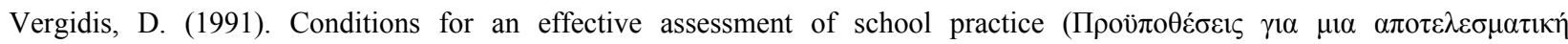

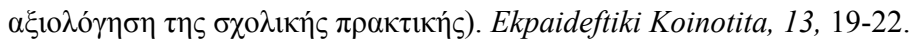

Vergidis, D. (1996). Evaluation of the "Melina" programme-Education and culture (A

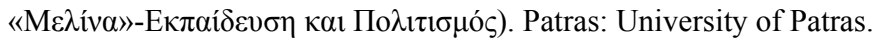

Vergidis, D. (2000). Lifelong learning and education policy. In Continuing education and lifelong learning: International

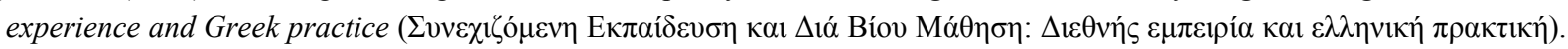
Athens: Atrapos.

Vergidis, D. (2001). The contribution of evaluation in education policy. In G. Bagakis (Ed.), Evaluation of educational programs

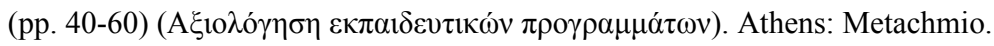

Vergidis, D., Glavas, S., Koutouzis, M., \& Fotopoulos, N. (2012). Greek educational system: Aspects and fundamentals of

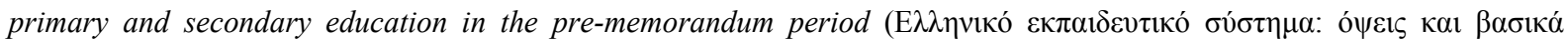

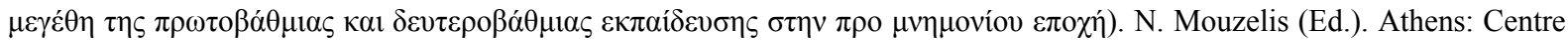
for the Development of Educational Policy-General Confederation of Greek Workers.

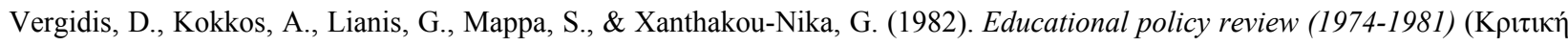

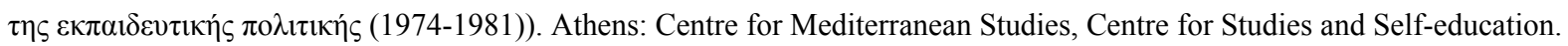

Vergidis, D., Vratsalis, K., Karatzia-Stavlioti, E., Katsillis, G., Kimourtzis, P., Kontogiannopoulou-Polydoridi, G., ... Stamelos, G.

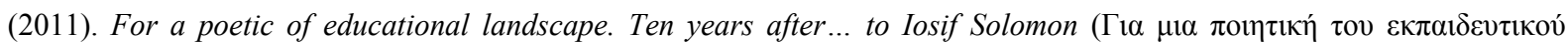

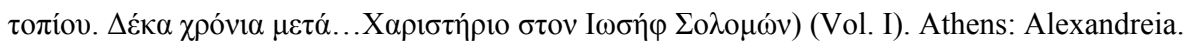

\section{International}

Baudrit, A. (2007). Training teachers on methods of cooperative learning: International. (E. Krommida, Trans.). Athens: Kedros Education.

Berger, G., Courtois, M., \& Perrigault, C. (2015). Folies et raisons d'une Universite. Paris: Petra, $\sigma .215$.

Bevort, A., \& Bucolo, E. (2006). Capital social. In J. L. Laville and A. D. Cattani (Dir.), Dictionnaire de l' autre économie (pp. 87-95). Gallimard-folio actuel: Desclée de Brower.

Candy, L., \& Edmonds, E. (1999). Introducing creativity to cognition (pp. 3-6). In E. Edmonds and L. Candy (Eds.), Proceedings of the 3rd Conference on Creativity \& Cognition. New York: ACM Press.

Chomsky, N. (2009). About a anarchism. (M. A. Alavanou, Trans.). Athens: Kedros.

Colombain, M. (1959). Cooperation. (N. Polyzos, Trans.). Athens: Higher Industrial Department.

De Angelis, M. (2013). Separating the doing and the deed. (S. Papazoglou \& S. Tsavdaroglou, Trans.). Retrieved from http://www.osdelnet.gr/book/1024805/

Dearden, R. (1984). Education and training. Westminster Studies in Education, 7, 57-66.

DeHaan, R. (2009). Teaching creativity and inventive problem solving in science. Life Sciences Education, 8(3), 172-181.

European Commission. (2004). Facing the challenge. The Lisbon strategy for growth and employment. Luxembourg: Office for Official Publications of the European Communities. 
European Commission. (2012). Entrepreneurship education at school in Europe. Retrieved from https://webgate.ec.europa.eu/fpfis/mwikis/eurydice/images/4/45/195EN.pdf

European Parliament. (2008). European Parliament legislative resolution of 23 September 2008 on the proposal for a decision of the European Parliament and of the Council concerning the European Year of Creativity and Innovation (2009). Retrieved September 23, 2009 from www.europarl.europa.eu

European Union. (1996). Teaching and Learning towards the society of knowledge. In the White Paper, EU.

European Union-Commission of the European Communities. (2003). Development of human capital for social cohesion and competitiveness in the knowledge society. 2003/C295/05.

European Universities Association. (2007). Creativity in higher education: Report on the European Universities Association Creativity project 2006-2007. Brussels/Belgium: European Universities Association.

Finke, R. A., Ward, T. B., \& Smith, S. M. (1992). Creative cognition: Theory, research and applications. Cambridge/London: MIT Press.

Gardner, H. (1993a). Creating minds: An anatomy of creativity seen through the lives of Freud, Einstein, Picasso, Stravinsky, Eliot, Graham and Gandhi. New York: Basic Books.

Gardner, H. (1993b). Multiple intelligences: The theory in practice (new ed.). New York: Basic Books.

Gardner, H. (2004). Frames of mind. New York: Basic Books.

Goldstein, I., \& Gessner, M. (1988). Training and development in work organizations. International Review of Industrial and Organizational Psychology, 43-72.

Hartley, D. (2003). New economy, new pedagogy? Oxford Review of Education, 29(1), 81-94.

Hocevar, D. (1978). Measurement of creativity: Review and critique. Manuscript submitted for publication.

Hocevar, D. (1979). The development of the creative behavior inventory. Paper present at The Annual Conference of Rocky Mountain Psychological Association, 16-19/4/1979.

International UNESCO Committee on «Education for the $21^{\text {st }}$ Century». (1996)

Kampylis, P. (2010). Fostering creative thinking: The role of primary teachers (Doctoral dissertation, University of Jyvaskyla, Jyvaskyla, Finland).

Kastoriadis, K., \& Cohn-Bendit, N. (1981). From ecology to economy. Athens: Kedros.

Latouche, S. (2014). Radical autonomy. Athens: Colleagues Editions.

Laville, L. (Dir.). (1994). L'Economie solidaire, une perspective international. Paris: Desclée de Brower.

Laville, L. (2000). L'économie solidaire. Une perspective internationale. Paris: Desclée de Brouwer.

Laville, L. (2003). Economie solidaire: les enjeux européens (pp. 27-35). Paris: Hermès.

Laville, L. (2011). Economie solidaire ed. les essentiels d'Hermès (CNRS Edition).

Laville, L. (2006). Dictionnaire de l'autre économie. Gallimard: Desclée de Brouwer.

Lawton, D. (1980). The politics of school curriculum. London: Routledge \& Kagan.

Lawton, D., Cains, R., \& Gardner, J. (Eds.). (2001). Education for citizenship. London: Typeset Ltd.

Lefebre, J. P. (2004). Productive forces according Marx. (A. Alefantis, Trans.). The citizen, 118, 40-44.

Lipiez, A. (2001). Pour le tiers secteur. Paris: La découverte.

Livingston, L. (2010). Teaching creativity in higher education. Arts Education Policy Review, 111(2), 59-62.

Lipiez, A. (2001). Pour le tiers secteur. Paris: La découverte.

MacPherson, J. (1997). Cooperative principles for 21th century. (K. Papageorgiou, Trans.). Athens: Institution for Cooperative Research and Studies.

Magyari-Beck, I. (1999). Creatology. In M. A. Runco and S. R. Pritzker (Eds.), Encyclopedia of creativity (pp.433-442). San Diego/London: Academic Press.

Ministerial Council on Education Employment Training and Young Affairs (MCEETYA). (2008). National declaration on educational goals for young Australians. Retrieved August 10, 2009 from www.mceecdya.edu.au/mceedya/melbourne_declaration.25979.html

National Advisory Committee on Creative and Cultural Education (NACCCE). (1999). All our futures: Creativity, culture and education. (DfEE. Sudbury).

OECD. (2001). Schooling for tomorrow. Paris: OECD, CERI.

OECD. (2003). Learning for tomorrow's world-first results from PISA 2003. Paris: OECD, CERI.

OECD. (2004). Problem solving for tomorrow's word. First measures of cross-curricular competences from PISA 2003. Washington DC: OECD. 
OECD. (2004). Education and equity. OECD Observer, February 2004.

Office for standards in education, children's services and skills (OFSTED). (2005). Creative partnerships: Initiative and impact, London, HMI 2517.

Oppenheim, A. N. (1992). Questionnaire design and attitude measurement, reprint. London: Heinemann Educational Books. Parnell, E. (2000). Reinventing of cooperation. (M. Fefes, Trans). Athens: Stohastis.

Roth, K. H., \& Papadimitriou, Z. (2013). Manifesto for a Europe of equality. (B. Tomanas, Trans.). Thessaloniki: Nissides. Sawyer, R. K. (2006). Explaining creativity: The science of human innovation. Oxford/New York: Oxford University Press. Solomon, R. (1985). Creativity and normal narcissism. Journal of Creative Behavior, 19, 47-55.

UNESCO. (1996). Education: The treasure within. Paris: UNESCO.

Vernon, P. E. (1989). The nature-nurture problem in creativity. In J. A. Glover, R. R. Ronning, and C. R. Reynolds, Handbook of creativity. New York: Plenum Press.

Ward, T. B. (2001). Creative cognition, conceptual combination and the creative writing of Stephen R. Donaldson. American Psychologist, 56(4), 50-354.

\section{Appendix: Sites}

www.create2009.europa.eu

www.oecd.org/edu/ahelo

ndt.oxfordjournals.org/cgi/content/full/gfm279v1

www.europarl.europa.eu/hearings/commission/2004.../cv_figel_en.pdf

http://www.oecd.org/edu/Greece_EAG2013\%20Country\%20Note.pdf

www.upatras.gr

www. researchranking.com

http://www.oecd.org/fr/education/scolaire/programmeinternationalpourlesuividesacquisdeselevespisa/pisa2006results.htm\#ES 